\title{
Extended Immersive Learning Environment: A Hybrid Remote/Virtual Laboratory
}

\author{
$\underline{\text { doi:10.3991/ijoe.v6s1.1386 }}$ \\ R. Marcelino ${ }^{1}$, J.B. Silva ${ }^{2}$, G.R. Alves ${ }^{3}$ and L. Schaeffer ${ }^{4}$ \\ ${ }^{1}$ SATC/Industrial Automation, Criciúma, Brazil \\ ${ }^{2}$ UNISUL/Informatics, Araranguá, Brazil \\ ${ }^{3}$ ISEP/Electrotechnics, Porto, Portugal \\ ${ }^{4}$ UFRGS/ Metallurgy, Porto Alegre, Brazil
}

\begin{abstract}
This paper presents a collaborative virtual learning environment, which includes technologies such as 3D virtual representations, learning and content management systems, remote experiments, and collaborative learning spaces, among others. It intends to facilitate the construction, management and sharing of knowledge among teachers and students, in a global perspective. The environment proposes the use of $3 \mathrm{D}$ social representations for accessing learning materials in a dynamic and interactive form, which is regarded to be closer to the physical reality experienced by teachers and students in a learning context. A first implementation of the proposed extended immersive learning environment, in the area of solid mechanics, is also described, including the access to theoretical contents and a remote experiment to determine the elastic modulus of a given object.These instructions give you basic guidelines for preparing camera-ready papers for conference proceedings. Use this document as a template if you are using Microsoft Word 6.0 or later. Otherwise, use this document as an instruction set. The electronic file of your paper will be formatted further. Define all symbols used in the abstract. Do not cite references in the abstract.
\end{abstract}

Index Terms-Distance learning, mechanical forming, remote experimentation and virtual learning environments.

\section{INTRODUCTION}

The human, scientific, commercial, intellectual and social opening movement, commonly referred as "globalization”, which deals with our current daily life, requires new attitudes from the educational community, namely on the teacher's role/competences, and on the teaching/learning process. In this globalization course, Information and Communication Technologies (ICT) and the Internet, in particular, have enabled the development of social platforms allowing all citizens to contribute to the generation of new knowledge and resources and also to their effective learning, use or perception, much in the line of a global giving-receiving perspective. In an educational perspective, the Internet has helped the involved stakeholders to better understand the students learning needs and the employers' expectations on their acquired skills and competences. In this context, the search for new teaching/learning solutions, namely educational tools based on the use of ICT, has proved beneficial to all stakeholders. The development of innovative and creative educational tools, readily available to the entire educational community, in a worldwide context, has contributed to the increment of existing bonds and the creation of new ones, in academia. This reality has thus been providing an added value to the teaching/learning process, in a global scale [1].

The educational landscape has been evolving in pace with technology. Figure 1 intends to depict this evolution from presential classes to current immersive learning environments (Web 3D), while passing through the (now intermediate) stages of distance learning - where Leaning Management Systems (LMS) prevailed - and collaborative learning (web 2.0 technologies). While some parts of the educational community are still working towards extracting the most out of the possibilities offered by web 2.0 technologies - namely increased users' collaboration, increased security in sharing information and resources, more powerful functionalities, and added support to creative applications, among other aspects [2] - other parts are now trying to address the new possibilities offered by 3D virtual worlds, accessible through the web. Mapping students learning styles into the organization and display of learning materials, building on student social connections for fostering discussion forums on learning goals or project-based activities, and exploring the sense of immersion provided by virtual worlds, represent some of the research lines currently being addressed by the educational community. In a simple sentence, the educational community is seeking to explore the potentialities of established and emergent web applications to increasingly motivate students for acquiring competences that may prove useful (if not essential) in a global market perspective.

In this paper we present a work-in-progress in this research line, combining the use of several web technologies

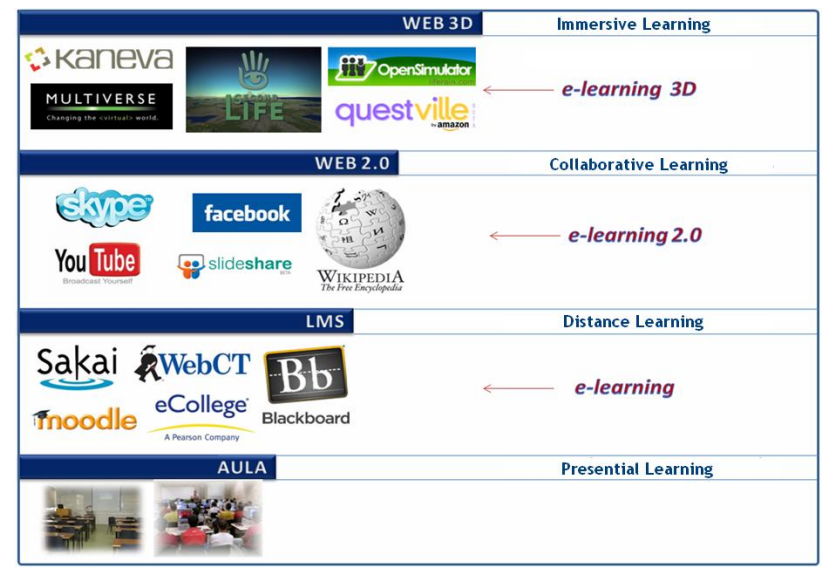

Figure 1. Teaching/learning environments and the web evolution. 
and the remote access to a real, physical experimental module.

\section{GOALS AND MOTIVATION}

Conducting experimental activities in a well-equipped laboratory is universally regarded as an essential skill to understand science \& engineering theories and concepts. However, it is also widely recognized that not all science \& engineering students have access to the same laboratory conditions, i.e. to the same type, quantity and diversity of laboratory instruments/apparatus. In many institutions, this lack of resources (in many cases caused by the number of students enrolled in a particular course) is addressed by two simple solutions [3]: the teacher conducts a series of demonstrations in the laboratory (requires less equipment) or the students are invited to conduct a series of simulations (requires no equipment, except for a simple PC equipped with the right software). In a number of situations, the teacher may choose to demonstrate a given theory or concept by conducting a remote experiment, either in the laboratory or in a normal classroom, by simply using a PC connected to the Internet and a video projector. Using the PC web browser the teacher accesses a remote laboratory and conducts a given experiment, thus demonstrating to the entire class the addressed physical/theoretical concept.

Related literature refers three different laboratory environments used in a teaching/learning process: (i) presential (hands-on) laboratories; (ii) remote laboratories; and (iii) virtual laboratories. A remote laboratory allows a remote client to actually control/observe a given experimental equipment/apparatus through a simple web browser [3]. A virtual laboratory allows the same actions and the same access mechanism, with the difference that the experimental equipment/apparatus is replaced by a computer model [4]. In sum, these two laboratory environments share the same principle, i.e. the use of ICT for facilitating the acquisition of laboratory competences by students with reduced or no access at all to convenient experimental equipment/apparatus.

From these facts, it seems acceptable that ICT can be used, in an effective manner, in a teaching/learning process. Our envisaged learning environment seeks to explore the resources presented by Internet-based laboratories (both remote and virtual), by following a reasoning principle that learning in itself, as a mental activity, is not committed to the classic (presential) classroom but can happen in any place and at any time a person is seeking for understanding/knowledge. In addition, the remote and simulated experiments contribute to cost savings and to the solving of time/space restrictions associated with real laboratories.

Summarizing, we propose an extended immersive learning environment combining the resources presented by remote laboratories and those offered by $3 \mathrm{D}$ virtual worlds, which also include collaborative mechanisms, for sustaining both presential courses (as a complement to practical activities) and distance courses (as a replacement of practical activities). The term "extended" is justified by the concern to include flexible and customized educational strategies, addressing the learning styles, motivations and competences of students, in an attempt to stimulate their development and their will to "learn how to learn", while also allowing the proposed environment to play an active role in the inner process of knowledge construction [1].

\section{USING VIRTUAL WORLDS AS IMMERSIVE LEARNING ENVIRONMENTS}

Three aspects have been contributing to an unprecedented communication and connectivity degree among citizens, at a global scale: (i) the increased (and everyday increasing) processing power of simple PCs, (ii) the increased (and increasing) bandwidth in residential communication networks, accessible to the general public, and (iii) the widespread use of the Internet and associated technologies. Some of these aspects have also enabled the implementation of distributed virtual environments, supporting collaborative mechanisms, on more or less affordable computational platforms. A collaborative virtual environment is a simulated world gathering geographically dispersed users, all connected through the Internet. Although geographically apart, all users share a common view of that world, which allow them to not only communicate but also collaborate and interact [5].

Virtual worlds can be regarded as virtual learning environments (a computational metaphor of a real learning environment) comprehending persons, locations, and objects basically allowing some form of interaction. Available functionalities, such as the existence of avatars, allow users to feel as part of the virtual world, thus creating a sense of "immersion". Virtual worlds can be used at different educational levels, like formal education, language teaching, and training of social skills, or even used for simple virtual meetings or gatherings. This sense of immersion is felt to be crucial for the effective conduction of remote experiments. Virtual worlds are in fact rich environments for providing a sense of immersion since they offer 3D representations, visual perspectives from each avatar, and interaction mechanisms.

This context facilitates the acquisition of knowledge and skills, providing that students are allowed to interact with the reality itself and from that interaction and the results provided by the real instruments and experimental apparatus infer valid scientific conclusions related to the observed phenomena. This approach allows students to actively participate in the search for knowledge, in a constructivist perspective [6]. Providing access to a remote laboratory, from a virtual world, thus allows:

- Students to experience a sense of immersion on the provided learning environment;

- Creating “bonds” between student(s) and teacher(s);

- Increasing students’ motivation;

- Navigating in the virtual world in any direction;

- Conducting real experiments;

- Interacting with objects of the virtual world, like moving things and opening doors, etc.;

- Doing the proposed activities according to the student own working rhythm or pattern;

- No time restrictions, i.e. students having to stop the experiment because the class is over.

Unlike currently available e-learning platforms or LMS - which support didactical contents in many different formats and media types, e.g. video, audio, animations, simulations, while also presenting an whole range of applications, e.g. chats, discussions forums, quizzes, among 
others - virtual worlds allow schools, universities and training centres to create a learning environment closely matching that of a real classroom or laboratory, i.e. with persons (teachers/students), a blackboard, a screen for presenting slides, tables and/or workbenches, chairs, equipment, etc., while also allowing for the support of basic behaviour rules. This clearly works against a cause of drop backs in science and engineering courses, i.e. a pure traditional educational process, which fails to observe or accommodate the expectations of natives born in the new digital era [7].

However, many authors observe that both virtual and remote labs fail to address the collaborative aspect [8]. This observation assumes students to access virtual/remote laboratories from their PCs without resorting to any type of communication or collaboration among them. In this perspective, a fundamental skill associated to laboratory work is missed: collaboration. Virtual worlds are also a promising environment, regarding this particular aspect, as they allow for (i) an augmented interaction among users and (ii) extended manipulation possibilities with the virtual objects present in a given world. Migrating from an environment where interactions occur mainly through text or diagrams into an environment that emulates the physical world and where interactions occur almost seamlessly from the user movements (like raising a virtual - hand or moving forward), provides an increased sense of immersion, to both teachers and students, which is regarded as a crucial factor to guarantee the success of remote labs. For instance, Kemp and Livingstone [9] state that compared to other electronic tools, environments such as OpenSimulator and Second Life may provide an increased "sense of location" (i.e. feeling as being there).

A laboratory for educational purposes should also be seen as a "community of learning", favouring all sorts of interactions between teachers and students, and among students themselves, in particular. Students are motivated to collaborate if they understand well their role and the partners' role, and also the benefits resulting from that collaboration. For instance, Hampel et al. [10] argue that for an effective knowledge building process it is vital that each student is aware of the activities done by his/her partner(s).

\section{The RexLab V Virtual World}

The proposed learning environment is based on a 3D virtual environment, accessible via Web, that allows students to feel as being in a traditional classroom, interacting with a teacher and other students, for building knowledge on a particular topic. Students can also collaboratively conduct remote experiments from within this 3D virtual world, to practice the theory and concepts learnt.

Figure 2 illustrates the proposed 3D virtual world, running on a simple PC, comprehending several software packages (a database, Moodle, Sloodle, and OpenSim) and the link to the remote experiment, supported by MicroWeb Servers (MWS). The proposed environment also aims to dissipate a general (wrong) feeling among youngsters that science and engineering are complicated, unappealing study matters.

\section{A. OpenSimulator}

OpenSimulator is a virtual world server that can be freely used to create and host 3D virtual environments,

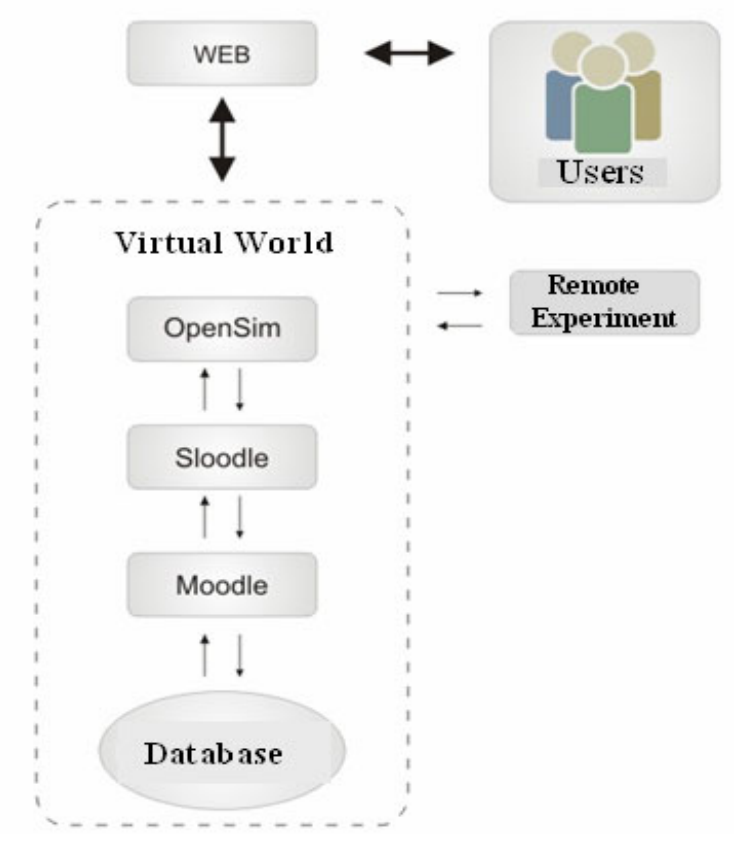

Figure 2. Proposed architecture

very similar to those made available by Second Life ${ }^{\mathrm{TM}}$, a world-renowned 3D virtual world community. OpenSimulator can be installed and run in a standalone mode or in a grid mode. According to Krinke [11], core developer of OpenSim, one can expect obtaining as most as $90 \%$ of the functionality offered by Second Life ${ }^{\mathrm{TM}}$. Its modular architecture allows an easy extension through plug-in modules, for accommodating more specific 3D interactive applications, when these are needed.

Regarding its application domains, OpenSimulator can provide a quite interesting structure for strengthening the teaching/learning process, and the communication and interaction mechanisms usually existing between teachers and students, and among students themselves, in particular. These mechanisms do help to sustain and even enhance dialogue and group work, in a pedagogical perspective, besides providing collaborative skills to the involved students. According to Peter Senge [12], working in group aims to stimulate the students' capacity for dialogue, i.e. "for the Greeks, dialogue stood as the free flow of meanings and perceptions that were difficult to attain by individuals alone.”

\section{B. MOODLE}

Moodle, which was originally developed by Dougiamas - a former administrator of WebCT ${ }^{\mathrm{TM}}$, is an open source LMS that allows users with programming skills to modify it or add modules, according to their own needs [13]. According to the same author, "the whole structure and development guidelines behind Moodle, are directed by social-constructivism principles".

According to Webwire (http://www.webwire.com), Moodle is "the worlds' fastest growing LMS", with over 50,757 active sites, in 214 countries, registered at its main website (http://moodle.org), as for July, 13 ${ }^{\text {th }}, 2010$ [14]. Also, according to Perrenoud and Thurler, the socialconstructivism principle behind Moodle is connected to a certain "vision for schools that aims to open to all the access to knowledge, develop individuals autonomy, their criticism, their competences as stakeholders in the general 
society, and their capacity to form and sustain points of view" [15].

\section{SLOODLE}

The Simulated Linked Object Oriented Dynamic Learning Environment (Sloodle), seeks to integrate the functionalities provided by an LMS like Moodle with that offered by a 3D virtual world, like OpenSim or Second Life $^{\mathrm{TM}}$. The term Sloodle, besides being and acronym, was also coined after the junction of the terms "Second Life" and "Moodle". In this environment (Sloodle), students can create their own contents that can be represented by $3 \mathrm{D}$ interactive objects. The integration level and the 3D interface made available by Sloodle allow for the possibility to shorten the differences between virtual and real classes, namely by (i) allowing students to use their avatars as a form of interacting among them and (ii) allowing them to interact with objects, which represent educational materials, in a more intuitive form [9]. The Sloodle structure is depicted in figure 3 .

\section{Virtual World $3 D$}

Figure 4 is a print screen of a typical virtual class, occurring in the proposed 3D virtual world, named as RexLab V. This in fact the latest instance of a series of interfaces and learning environments built around the concept of remote laboratories.

The RexLab V environment was developed with OpenSimulator, whereas Moodle is responsible for storing and managing the educational contents. Sloodle is used to establish a bridge between Moodle and OpenSimulator. Finally, students have access to the remote laboratory, through the virtual worlds client application, i.e. in our case Hippo Viewer (freely available for download at http://mjm-labs.com/viewer). Guest visitors may access the RexLab V 3D virtual world, by inserting the following information in the Hippo Viewer Edit menu:

- Login URL: http://200.135.36.28:9000/

- Platform: OpenSim

- GridNickName: satc

- Grid Name: SATC

- First name: aluno

- Last name: teste

- Password: aluno123

\section{E. The Remote Experiment}

Unlike a virtual laboratory, where all processes are simulated, a remote experimentation laboratory allows users to interact with real, physical processes, which provides them the ability to analyze real world practical experiments. In fact, Cassini states this chance in [7], pointing out that users are able to discover new results, as they need to set up and calibrate the remote equipments with their own set of data. With this aspect in mind, we selected an experiment for determining the Young's, or elastic, modulus, to be the first one to be made remotely accessible through the RexLab V virtual world. In solid mechanics, the Young's modulus is a measure of the stiffness of an isotropic elastic material. The Young's modulus is defined as the ratio of the uniaxial stress over the uniaxial strain in the range of stress in which Hooke's Law holds [16]. This can be experimentally determined from the slope of a stress-strain curve created during tensile tests

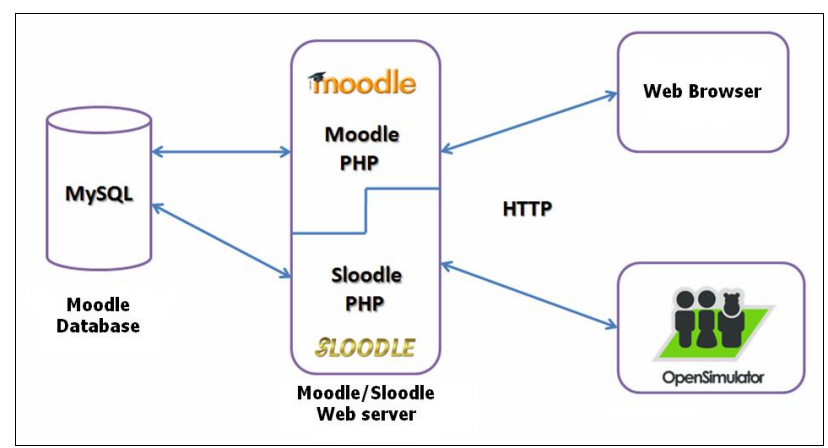

Figure 3. Sloodle structure ${ }^{1}$

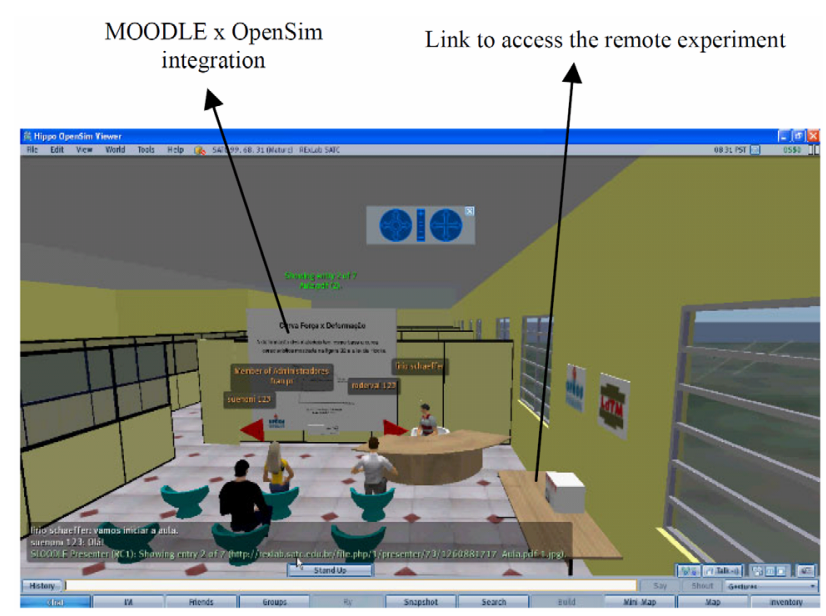

Figure 4. The RexLabV virtual world

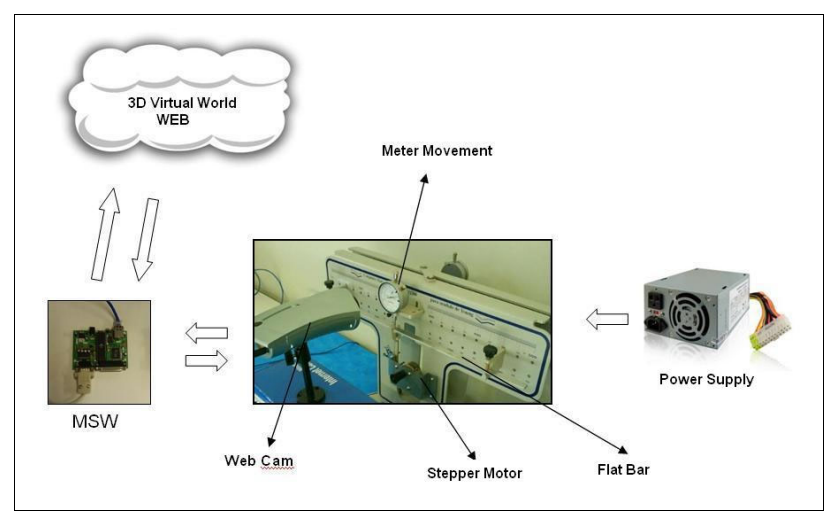

Figure 5. Apparatus of the remote experiment on Young's modulus.

conducted on a sample of the material. For this particular remote experiment, we implemented the apparatus depicted in figure 5 , which enables measuring the elastic modulus of a flat bar.

\section{REMOTE ACCESS TO THE EXPERIMENTAL APPARATUS}

As previously stated, the aim of this remote experiment is to allow students to check the theory behind the elastic modulus, namely to allow them to analyse the factors that influence the twisting of a flat bar and to establish the relation between the bar torsion and the applied force.

A series of automating procedures and equipment had to be deployed to allow the remote control/observation of

\footnotetext{
${ }^{1}$ Source: Adapted from http://slisweb.sjsu.edu/sl/index.php/sloodle
} 
the experimental apparatus. These equipments were later connected to the 3D virtual worlds server to allow their control/observation through that environment. In particular, the control part is provided by a stepper motor that twists the flat bar under analysis while a webcam pointed to the measuring equipment provides the feedback to the user. MWS are used to establish the connection between the remote users and the automation devices, through web accessible interfaces.

To access the remote experiment, users click on the object box "remote experiment", located inside the RexLab V 3D virtual learning environment. This causes a web interface to pop up, and in this new page users can control the force application by selecting one of a series of control buttons indicating the force that will be applied to the flat bar by the stepper motor. Figure 6 illustrates the interface that is displayed to remote users, containing 3 control buttons (forces of $100 \mathrm{~g}, 200 \mathrm{~g}$, and $300 \mathrm{~g}$ ) and a visualization box for displaying the video stream coming from the webcam. By applying different force values and noting down the results indicated by the measuring equipment (see figure 6), users extract information for calculating the elastic modulus. Depending on the proposed exercise sequence, users can later on compare their conclusions against those obtained through a theoretical analysis or vice-versa.

\section{CONCLUSIONS AND FINAL REMARKS}

The work described in this paper was partially motivated by the educational potentialities offered by the new ICT, namely the access to information, its interactive manipulation, and the possibility to derive new knowledge and skills from that very same interactive process. The full exploration of these new potentialities implies new educational strategies, new didactical approaches and also new pedagogical theories. Furthermore, the social competences and skills acquired during the utilization of these $3 \mathrm{D}$ virtual learning environments can be an added value if later used in a personal and/or professional perspective. Again, the ancient principle that schools prepare students for life is also applicable to the use of $3 \mathrm{D}$ virtual worlds in an educational perspective.

It should be emphasized that many teachers, nowadays, feel attracted by the number and potentialities of currently available educational technologies/resources and have actually been using them to exercise their teaching role, while addressing a students' reflexive learning perspective. These teachers seek to provide students with new skills and competences they think to be essential in a global communicating world, where the use of social networks is part of the daily life, not only in a person's private life but also in many professional aspects, especially in corporations operating worldwide.

The developed 3D virtual learning environment seeks to provide a new perspective in the educational landscape by exploiting the potentialities offered by the combined educational resources. Our aim was to provide an integrated solution based on a learning model fostering the active participation of all stakeholders. First results regarding the environment performance indicate a simple PC to be enough, i.e. the installed applications (Moodle, Sloodle, and OpenSimulator) run perfectly well on a widely accessible and affordable PC.

Several students have already accessed the provided 3D virtual world on a pure experimental basis, and have re

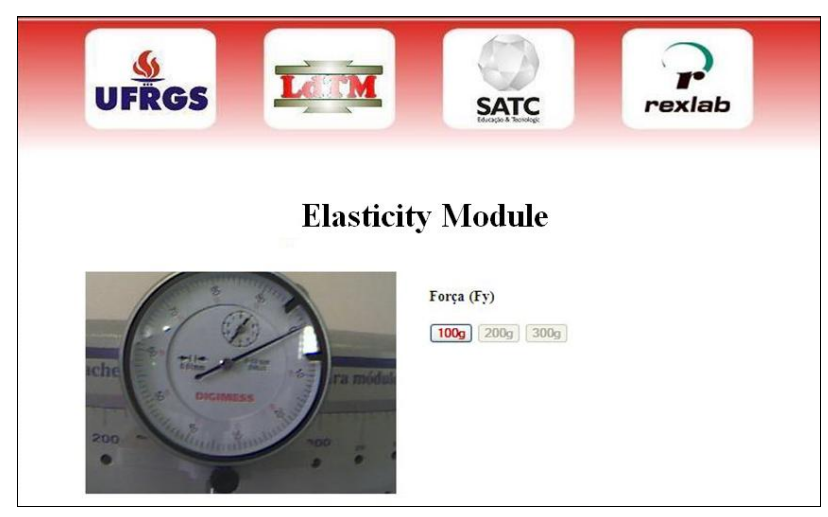

Figure 6. Web Interface

ported a genuine interest and curiosity with the new learning environment. The major strength seems to reside on the level of interaction provided by the learning environment, namely by the possibility to have an avatar navigating through the virtual world.

The following development steps will target the adoption of the proposed learning environment on an entire degree on science and engineering, to extend the scope and representativeness of students' feedback. We are researching also the use of virtual world in a grid mode.

\section{REFERENCES}

[1] Silva, J. B., Alves, J. B. M., and Giraldi, M. A utilização da experimentação remota como suporte a ambientes colaborativos de aprendizagem. In: ICBL - International Conference on Blended Learning, Florianópolis-SC, Brazil, 2008.

[2] T. O’Reilly, Web 2.0 Compact Definition: Trying Again. [online][Accessed 21/11/2007]. Available at: http://www.oreillynet.com/archives/2006/12/web_20_compact.ht ml.

[3] Alves, G. R.; Ferreira, J. M.; Müller, D.; Herbe, H.; Hine. N. ; Alves, J. B. M.; Pereita, C. E.; Chiang, L.; Herrera, O; and Sucar, E. Remote Experimentation Network - Yielding an InterUniversity Peer-to-Peer e-Service. In: International Conference on Emerging Technologies and Factory Automation (ETFA), Catania, Italy, 2005.

[4] Corter, J. E.; Nickerson, J. V.; Esche, S. K., Hassapis, C ; IM S., MA, J. Constructing reality: a study of remote, hands-on, and simulated laboratories. ACM Transactions on Computer-Human Interaction. Vol 14, No 2, Aug. 2007.

[5] B. Rohel, "Distributed Virtual Reality - An Overview”, 1995.

[6] W. Joolingen. Cognitive tools for discovery learning. International Journal of Artificial Intelligence in Education, 1999.

[7] Cassini, M.; Prattichizo, D. E-Learning by Remote Laboratories: a new tool for controle education. The 6th IFAC Conference on Advances in Control Education, Finland, 2003.

[8] Nedic, Z.; Machokta, J. , Nafalski, A. Remote laboratories versus virtual and real laboratories. In: Proceedings of the 2003 33rd annual frontiers in education conference. Boulder, CO. 2003.

[9] Kemp. J, Livingstone, D. - Putting a Second Life "metaverse" skin on leaning management systems (Sloodle whitepaper). [online][Accessed 27/12/2007]. Available at: http://www.sloodle.com/whitepaper.pdf

[10] Hampel, T.; Selke, H. ; and Vitt, S. Deployment of simple usercentered collaborative technologies in educational institutions experiences and requirements. In: Proceedings of the 14th IEEE International Workshops on Enabling Technologies: Infrastructure for Collaborative Enterprise. 2005.

[11] OpenSim, “The Open Simulator Project”, http://opensimulator.org. Accessed 29/09/2008.

[12] Senge, Peter M. A quinta disciplina. 7.ed. São Paulo: Best Seller, 2000 . 
[13] Douguiamas, M. - Moodle; a case study in sustainability [online][Accessed 27/12/2007] Available at: http://www.osswatch.ac.uk/resources/cs-moodle.xml

[14] Webwire. - Webwire: O’Reilly Releases “Using Moodle”, Second Edition: Extendind the Chalt-and-task Classroom with the Open Source CMS. [online][Accessed 15/11/2007]. Available at: http://www.webwire.com/viewpressrel.asp?aID=53747

[15] Perrenoud, P., Thurler, M.G. - As competências para ensinar no século XXI. Porto Alegre, Brazil: Artmed, 2002.

[16] L. Schaeffer. Conformação Mecânica. 2. ed. Porto Alegre, Brazil: Imprensa Livre, 2004. 167 p.

\section{AUTHORS}

R. Marcelino, is a doctorade student at Universidade Federal do Rio Grande do Sul (UFRGS), Porto Alegre, Brazil. (e-mail: roderval.marcelino@satc.edu.br).
J.B. Silva, is a senior researcher at Universidade do Sul de Santa Catarina (UNISUL), Araranguá, Brazil. (e-mail: juarez.silva@unisul.br).

G.R. Alves, is a senior researcher at Instituto Politécnico do Porto - Escola Superior de Engenharia (IPP/ISEP), Porto, Portugal. (e-mail: gca@isep.ipp.pt).

L. Shaeffer, is a senior researcher at Universidade Federal do Rio Grande do Sul (UFRGS), Porto Alegre, Brazil. (e-mail: schaefer@ufrgs.br).

This article was modified from a presentation at the REV2010 Conference at KTH, Stockholm, Sweden in June 2010. Submitted July 15th, 2010. Published as resubmitted by the authors July 29th, 2010. 